\title{
ON ROUGH SET THEORY ON ACHIEVING HIGH QUALITY CABLE MATERIAL PRODUCTION BY GREEN LOW CARBON TECHNOLOGY
}

\begin{abstract}
As the second largest machinery industry, the energy-intensive cable industry not only creates a lot of economic value but also consumes a lot of energy. It is an inevitable requirement to promote the technological development of the industry in the new era to improve the quality and efficiency and realise industrial energy-saving and consumption reduction. In order to obtain good strength and conductivity, the metal rods of cable are usually heat-treated for several hours or even several days after the rods are extruded, this is a major energy consuming process in traditional production. Based on the background, this study adopted the energy-saving equal-channel angular pressing (ECAP) technology to replace the traditional heating treatment process, and converted the simple heat conduction with thermo-mechanical energy transfer, so as to realise the good strength and conductivity matching of the cable aluminum alloy material. In this study, energy-saving ECAP technology is used to replace the traditional heat treatment process, and heat-mechanical energy transfer is used to replace the simple heat conduction, so as to achieve good strength and conductivity matching of cable aluminum alloy material. The results show that the suitable ECAP process routes can improve the microstructure of aluminum alloy with higher strength and conductivity than the traditional heating process. The research results can be used for technology upgrading and low carbon production in cable industry due to the significantly time reduction of the energy-consuming heat treatment and the high-efficient obtainment of high-quality production.
\end{abstract}

Keywords: low carbon production, energy-saving, ECAP, aluminum alloy, high quality cable

\section{Introduction}

Due to its good strength, ductility, corrosion resistance and electrical conductivity, aluminum alloys have been extensively used in the power transmission industries, which is the second largest machinery industry in China [1-6]. However, some of these properties seem contradictory and cannot achieve the high level at the same time. For example, the high strength is usually achieved with the sacrifice of ductility [7, 8]. Also, the increase of the strength often leads to the decrease of the electrical conductivity, because the solid solute atoms, precipitates, dislocations and grain boundaries that support the high strength are also the main sources of electron scattering [9-11]. In order to balance these contradictions and achieve the good match of strength and electrical conductivity, researchers usually adopt the heating treatment to reach the better comprehensive properties of materials, such as artificial aging [12, 13], annealing [14-16]. However, the several hours' or even several days' heating treatment processing not only restricts the production

\footnotetext{
${ }^{1}$ Institute of Materials Processing and Intelligent Manufacturing, College of Materials Science and Chemical Engineering, Harbin Engineering University, Harbin 150001 China

${ }^{2}$ Department of Mechanical Engineering, Kafrelsheikh University, Kafrelsheikh 61519, Egypt

* Corresponding authors: 1z_heu@hrbeu.edu.cn (Z. LI), lili_heu@ @rbeu.edu.cn (L. LI)
} 
efficiency but also consumes a lot of energy, which goes against the modern concept of efficient and green low carbon [12-16]. Therefore, instead of the traditional high energy consumption long-time heating treatment, the idea of new technology adapting to the low carbon and energy-saving is gradually taking shape.

In the past decades, researchers [8-11] have developed the severe plastic deformation $(S P D)$ processes, including equal channel angular pressing (ECAP), high pressure torsion $(H P T)$, which obtain the ultra-fined grains in alloys and is an efficient and low carbon technology. Under the action of external force, the material through the special die can achieve significant grain refinement, which can refine the internal structure of the material to submicron or even nanometer size [8-14]. The purpose of SPD methods is improving the material properties, such as strength, wear resistance, corrosion resistance and electrical conductivity by the microstructure refinements [11-14]. Valiev et al. [14] have proposed a new strategy to design the well-combined strength and conductivity in the AA6201 (Al-Mg-Si) alloys based on the intelligent manipulation by grain refinement during $H P T$ at room temperature and subsequent precipitates during $H P T$ at elevated temperatures. The higher ultimate tensile strength (UTS) of $365 \mathrm{MPa}$ and conductivity of $58.4 \%$ were obtained through the optimum thermo-mechanical processing routes. Nevertheless, the HPT technique is only suitable for small size sample research and is difficult to be produced in industrial scale. Also, there are rarely published papers focus on ECAP in the different aluminum alloys, which is the most potential $S P D$ method to implement the large-scale industrial production [17-20].

Based on this background, Al-Fe alloy used as the conductor for the power transmission cable were investigated. The purposes of this study are firstly aimed at the production of Al-Fe alloy processed by low carbon ECAP technology, and secondly explored an optimum ECAP route to achieve the simultaneous improvement of the strength and conductivity in this alloy.

\section{Methods}

Commercial semi-manufactured AA8176 aluminium alloy rods with chemical compositions, in wt. \%, of Al-0.47Fe-0.096Si-0.1Zn were used in this study. As shown in Figure 1, the as-received alloy rods subjected to ECAP at room temperature $(R T)$ and elevated temperature $(E T, 423 \mathrm{~K})$, respectively. ECAP die is composed of two channels with the same shape and the same section intersecting each other according to a considerate angle. When it works, the billet passes from one channel to another under the pressure of the plunger. A large amount of pure shear deformation is introduced into the material during this process to achieve grain refinement. For elevated temperature processing, the rods were firstly kept warm in the temperature field provided by the furnace for $10 \mathrm{~min}$ to ensure the uniform temperature in centre and surface of the sample. Route $B c$ in which the sample is rotated by $90^{\circ}$ in the sense between each pass was used. The ECAP was conducted using a pressing speed of $25 \mathrm{~mm} \mathrm{~s}^{-1}$ and a splite die with an internal channel angle of $90^{\circ}$ and an outer arc of curvature of $90^{\circ}$ so that an equivalent strain of near 1 was imposed on the sample in each separate pass [20]. Finally, the sample of 1, 2, 4, 6, and 8 passes of ECAP at $R T$ and $E T$ was successfully achieved. Compared to the traditional heat treatment process, which requires 24 hours of furnace heating, the ECAP method can produce the final rods product within 1.5 hours. The thermo-mechanical energy processing 
is obviously more efficient and energy-saving due to the significantly time reduction of the energy-consuming heat treatment.

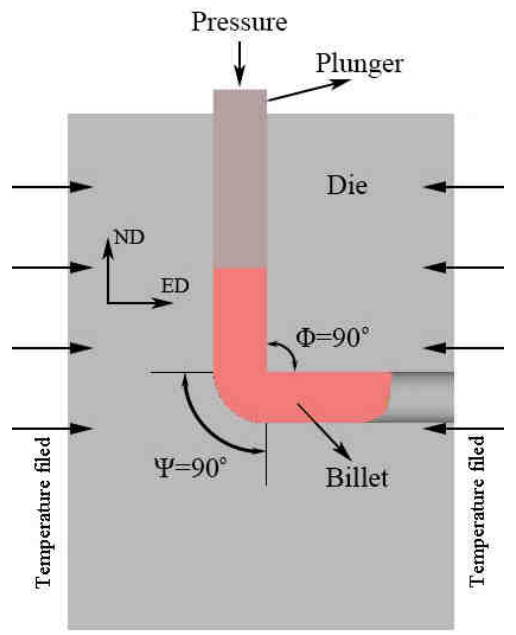

Fig. 1. Schematic illustration of the ECAP processing and the geometry of the used die

Following ECAP, the dog-bone shape specimens with a gauge length of $10 \mathrm{~mm}$ prepared for tensile testing were cutting by wire electrical discharge machining as the extrusion direction. The testing conducted on INSTRON 3365 universal testing machine at a speed of $0.001 \mathrm{~s}^{-1}$ to examine the mechanical properties. The $0.2 \%$ yield strength $(Y S)$, ultimate strength $(U T S)$ and elongation of fracture $\left(\varepsilon_{f}\right)$ were derived from the results. The specimens were sectioned on the $\mathrm{Z}$ plane perpendicular to the normal axes and then meshed and carefully polished to a mirror-like finish for the electrical conductivity (\% IACS, International Annealed Copper Standard) detection using eddy current electrical conductivity tester (FIRST FD-102). The device was calibrated before each measurement with reference samples providing an accuracy of $\pm 0.3 \%$ on the measured conductivity.

Microstructures of the sample before ECAP was also observed in the $\mathrm{Z}$ plane through the Transmission electron microscope (TEM), JEM-2100. The examination operated at $200 \mathrm{kV}$ to obtain the microstructure of specimens subjected to 8 passes ECAP. Thin foils for TEM were meshed down to about $100 \mu \mathrm{m}$ thick by mechanical grinding using grit papers ranging from 600 to 2000 mesh. Subsequently, the ion beam thinner was used to achieve the final electron transparency by the argon-ion.

\section{Results}

\section{Mechanical properties and electrical conductivity after the energy-saving technology}

Figure 2 presented the tensile results and Figures $2 \mathrm{a}$ and $\mathrm{c}$ were the stress-strain curves of the AA8176 alloy subjected to different ECAP passes at room temperature and elevated temperature, respectively. Evolution of yield strength, ultimate tensile strength, and elongation to fracture derived from the corresponding stress-strain curves were shown in Figures $2 b$ and $d$. 
It can be noticed from the curves of specimens processed by ECAP at $R T$ in Figure 2a, stress flow reached the maximum after a short uniform deformation stage, following entered a post-uniform deformation stage accompanied by working softening and then presented a rapidly fall and fracture. The evolution of UTS in Figure $2 \mathrm{~b}$ showed the significant increase in 1 pass ECAP and the slow ascending in 2 passes. Subsequent passes represented a nearly stable tendency which indicated the saturation of UTS. Meanwhile, the saturation of elongation also achieved after 2 passes ECAP as a decrease in 1 pass and a slight recovery in 2 passes. Stress-strain curves of specimens subjected to 1 and 2 pass ECAP at ET (Fig. 2c) were similar to that in $R T$ ECAP. But the gradually distinct yield points were displayed in curves of 4,6 , and 8 passes together with the increase in UTS. Corresponding to the continuously increased strength in Figure $2 \mathrm{~d}$ with the sacrifice of the elongation.

a)

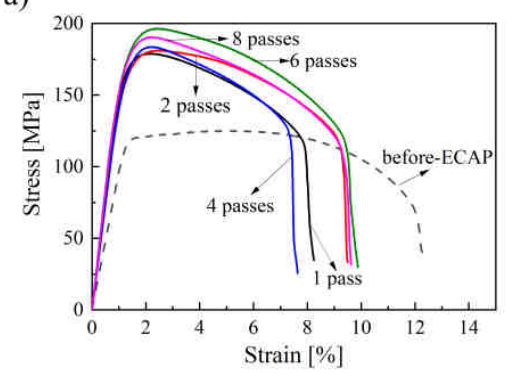

c)

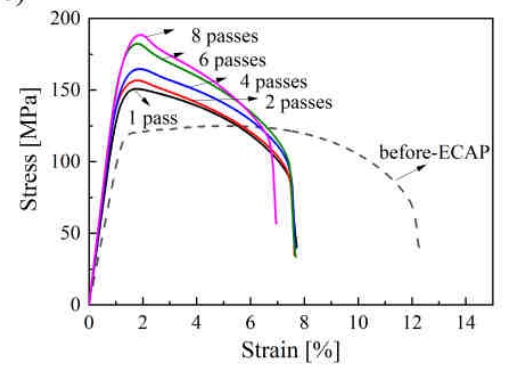

b)

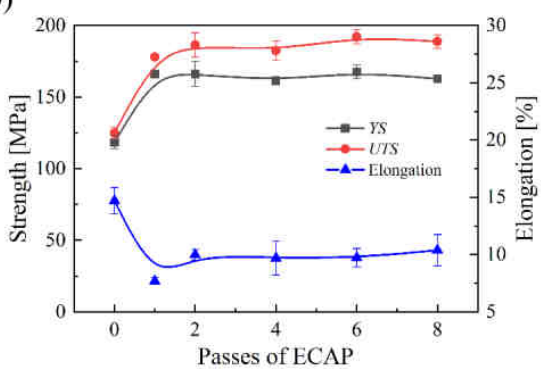

d)

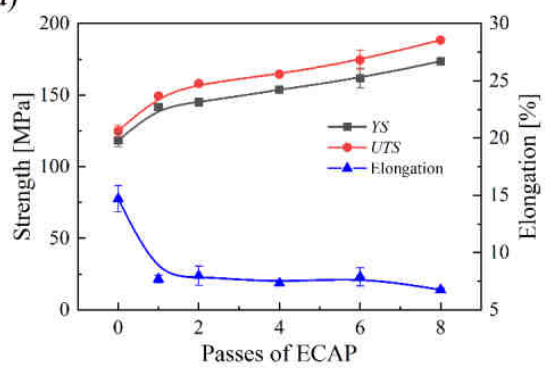

Fig. 2. The stress-strain curves and variation of mechanical properties of the Al-Fe alloy processed by different passes ECAP at: a), b) room temperature and c), d) elevated temperature

Electrical conductivity is significantly important for the power conductor material, and it is inversely proportional to electrical resistance. Figure 3 was the electrical conductivity evolution of this investigated alloy processed by different passes of ECAP at $R T$ and $E T$, respectively. It can be seen the value goes through a process of gradual decrease to $59.58 \%$ in 6 passes followed by partial recovery to $59.95 \%$ in 8 passes during the ECAP at $R T$. However, the electrical conductivity evolution of ET ECAP contains an additional ascent stage in the early period with the subsequent faster reduction to $59.45 \%$ at 6 passes. The recovery of electrical conductivity also was observed in 8 passes ECAP at ET. However, the electrical conductivities measured in 8 passes of both the two temperatures 
are lower than that of the before-ECAP, which deserved to take measures to further improve.

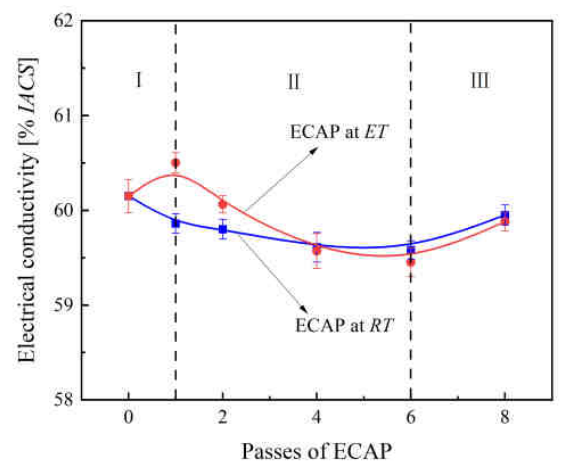

Fig. 3. The electrical conductivity evolutions of the Al-Fe alloy subjected to different passes ECAP at room and elevated temperature

\section{The effect of thermo-mechanical energy processing on microstructure}

Figure 4 was the TEM images of Al-Fe before ECAP and subjected to 8 passes ECAP at the two temperatures. It can be seen in Figure $4 \mathrm{c}$ that the elongated subgrain microstructure with the micron precipitates, which have been demonstrated as the $\mathrm{Al}_{3} \mathrm{Fe}$ and $\mathrm{Al}_{6} \mathrm{Fe}$ in our previous work [18], is observed in before-ECAP specimens. Besides, some nano-precipitates and dislocation are found and indicated by the black arrows in Figure $4 \mathrm{~b}$. After 8 passes ECAP at room temperature, significant grain refinement has reached to average subgrain size of less than $1 \mu \mathrm{m}$. The micron precipitates fragment, a lot of nano-particles and dislocations were examined and indicated the strong interaction between the precipitates, dislocations and grain boundaries. Similar microstructure characteristics were also observed in ET ECAP, in contrast, the finer and well-defined grain size was noticed in Figure 3e.

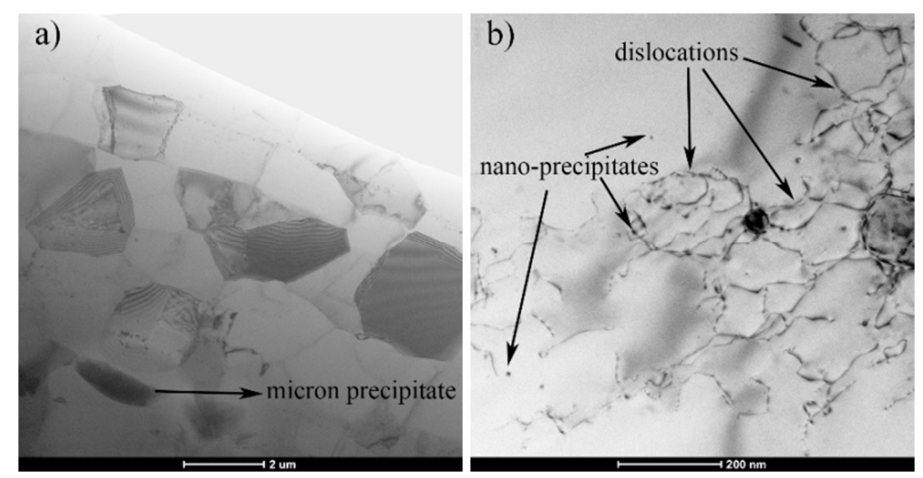




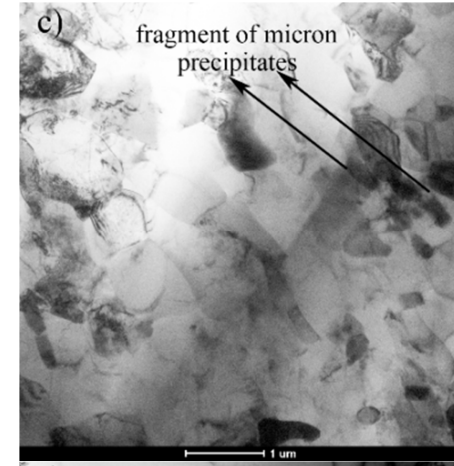

e)

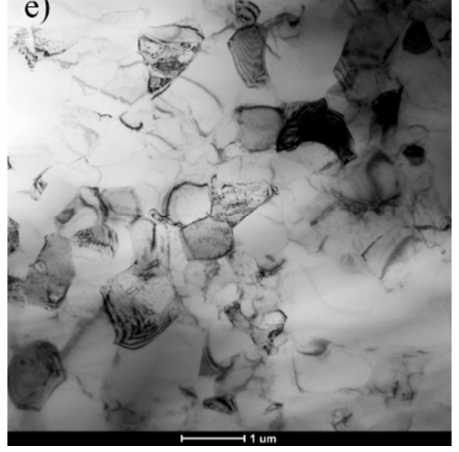

d)
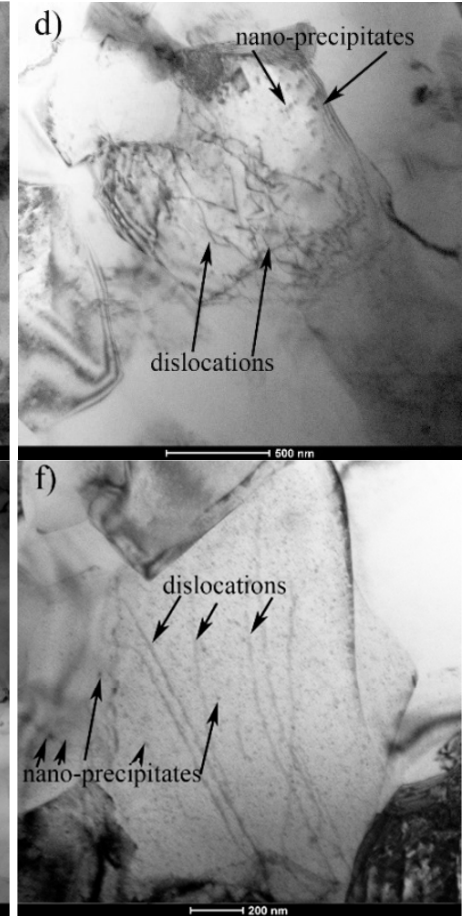

Fig. 4. TEM images of Al-Fe alloy: a), b) before ECAP; c), d) subjected to 8 passes ECAP at room temperature and e), f) subjected to 8 passes ECAP at elevated temperature

\section{Discussion}

\section{Evolution of strength and electrical conductivity}

It has been demonstrated in our previous study [18], there are four procedures in this investigated alloy during the ECAP: dislocation generation and annihilation, grain refinement, micro precipitates redissolution, and nano-particles precipitation. The distinctions lie in the fact that the dissolution is more intense under the ECAP at ET, leads to the changes in microstructure evolution.

During the early period of ECAP at $R T$, the significantly increased dislocation density and grain refinement contribute to the remarkable improvement of both the yield strength and ultimate tensile strength in 1 pass. With the following passes, the gradual saturation of dislocation density and grain refinement caused the saturation of UTS. During the ECAP at $E T$, whereas the limited increase in strength of 1 pass associated with the elevated processing temperature, an obvious work hardening rather than the room temperature was observed in subsequent passes, bringing in a continuous increase in strength to the same level in 8 passes as the $R T$. This is related to the segregation of solute atoms caused by precipitates redissolution, which leads to an incremental dislocation density.

The electrical property variations have been shown in Figure 3. The electrical resistance is caused by the scattering between the free electrons and the lattice atoms. There is a significantly important relationship between the crystal microstructure and the 
resistance, that can be described by the well-known Matthiessen rule [9], which is presented as:

$$
\rho_{\text {total }}=\rho+\rho_{s s}+\rho_{p}+\rho_{\text {dis }}+\rho_{g b}
$$

where $\rho_{\text {total }}$ is the total electrical resistance, $\rho$ is the electrical resistivity of the lattice, $\rho_{s s}$ is the resistivity due to solute atoms dissolved in the matrix, $\rho_{p}$ is the resistivity added by the precipitates, $\rho_{d i s}$ is resistivity due to dislocations present in the microstructure, and $\rho_{g b}$ is the resistivity due to grain boundary.

It can be indicated that all the four strengthening mechanisms mentioned above lead to an increase in electrical resistivity. It is accepted that the scattering of solution atoms is the most influential factor in the degradation of electrical conductivity while the dislocation has less effect. The electrical conductivity values firstly decreased to the minimum at 6 passes ECAP at $R T$ due to the increased scattering of grain boundaries, dislocation, and especially redissolved solute atoms. Then, the grain refinement and dislocation density reached saturation. The enhanced coordination effect of fine grains could release the strain around micron precipitates during the deformation, which makes it difficult to accumulate high-density dislocation near the micron precipitates and inhibits the particle fragmentation and redissolution process. So, the recovery of the electrical conductivity caused by precipitation of nano-particles became rather than the reduction arisen from the redissolution, resulting in the partial recovery of value in 8 passes. In addition, there were two points worthy of nothing in ECAP at ET. The first was the increase of electrical conductivity in 1 pass associated with the precipitation of nano-particles under the combined effect of the elevated temperature and enough dislocation, which provide sufficient diffusion energy and paths. Another was the more rapid reduction during the 2 to 6 passes related to the strong redissolution in ET ECAP, we have mentioned above.

\section{Simultaneously improve the strength and electrical conductivity through the energy-saving technology}

In this section, the modification of conventional ECAP routes by changing the temperature during the processing will be studied to simultaneously improve the strength and electrical conductivity of the investigated alloy. AA6021 alloy processed by HPT at RT with followed $H P T$ at $130{ }^{\circ} \mathrm{C}$ has been researched by Valiev et al. [7, 14]. The simultaneous increases of the UTS to $412 \mathrm{MPa}$ and the electrical conductivity to $55.6 \%$ IACS have achieved by contrast to the UTS of $\sim 330 \mathrm{MPa}$ and the electrical conductivity of $\sim 53.6 \%$ IACS in the coarse grains alloy. Some additional samples were processed by different modified ECAP to verify the theory we proposed above. For convenience, the sample nomenclatures are summarised in Table 1 with the corresponding processing parameters. Tensile test and electrical conductivity test was also conducted to acquire the strength and electrical conductivity of these samples and listed in Table 1.

Firstly, followed the routes of Valiev, samples subjected to condition 1 were obtained, condition 2 was also used as a comparison. Just like the $R T$ and $E T$, the increase in strength was also achieved, but the conductivity was still lower than the before-ECAP. These results are different from the AA6201 alloy due to the diversities of redissolution and precipitate between the two alloys. So, the suitable modified method should base on the characteristics of the microstructure evolution of this Al-Fe alloy. It is clear from Figures 2 and 3, the main restriction condition for the simultaneous increase is the deficiency of electrical 
conductivity. Therefore, the next discussion should focus on the improvement of electrical conductivity.

A more detail analyst on the variety of electrical conductivity has been conducted. The curves were divided into three parts as indicated in Figure 4. In part I, the electrical conductivity rose to $60.50 \%$ IACS in ET was observed due to the help of elevated temperature and high-density dislocation. In part II, the ECAP at $R T$ exhibited a slower reduction to the minimum. And in the part III, the part recovery displayed in both the two temperatures. However, it can be noted part III in ET also own the elevated temperature and the high dislocation density but hasn't shown the faster recovery rate as the part I. This can be explained based on the segregation of redissolution solute atoms during the ECAP. The more significant segregation during the ET ECAP, due to the strong redissolution, were observed in this investigated alloy [18-20]. The limited available dislocation in the vicinity of the segregation decreased the average diffusion paths to precipitate, and hence inhibited the precipitation and recovery process in part III. To verify this point, samples with condition 3 were prepared for it provided a microstructure with less segregation in 6 passes. The higher electrical conductivity of $60.07 \%$ IACS than the RT demonstrated that there is more significant precipitation in subsequent ET ECAP. This result is a piece of persuasive evidence to support our point. Besides, it was noticed that condition 3 exhibited higher electrical conductivity compared to condition 1 . Samples with condition 4 were manufactured to identify if the more passes $R T$ ECAP is more helpful to the subsequent precipitate in ET ECAP. The higher conductivity value of $60.18 \%$ IACS suggested this idea due to the less dissolution in only a single ECAP pass at ET.

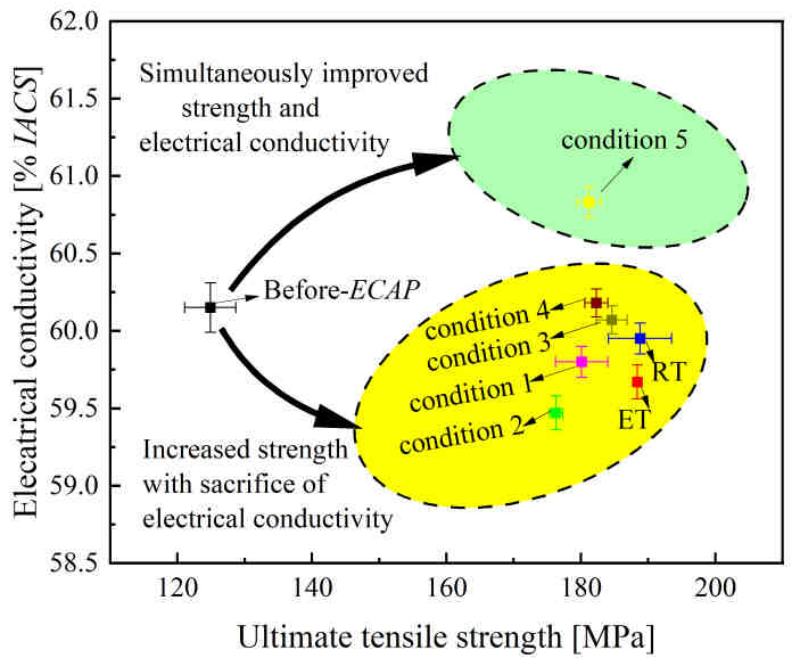

Fig. 5. The electrical conductivity versus ultimate tensile strength for the Al-Fe alloy subjected to different ECAP conditions

Consequently, a suitable route design of condition 5 was proposed as combined with the advantages of $R T$ and $E T$ in the three parts. The first single pass at ET contributed to the high electrical conductivity and partial the increase in strength. Then, an additional 6 passes at $R T$ restricted the reduction in electrical conductivity and provided another part of 
strength increase and the preparation of microstructure for the next pass. The final single pass at ET offset the performance degradation caused in the previous processing process. The result shown in Table 1 exhibited a simultaneous improvement of strength and electrical conductivity was successfully achieved under condition 5. The electrical conductivity versus ultimate tensile strength in Figure 5 summarised all the discussed ECAP conditions of this alloy, it is clearly presented the increased mechanical strength as well as electrical conductivity in conditio 5 compared to the other conditions. It demonstrates a modification of conventional ECAP sequence can be more widely used to simultaneously enhance the strength and the electrical conductivity and strength to get the high quality Al alloy used in cable. Also it saves energy in the production, which follows the sense of improve the quality and efficiency and realises industrial energy-saving and consumption reduction [21-29].

Table 1

Sample designation, processing parameters, and corresponding mechanical property and electrical conductivity of the Al-Fe alloy

\begin{tabular}{|c|c|c|c|}
\hline Sample & Processing condition & $\begin{array}{c}\text { UTS } \\
{[\mathbf{M P a}]}\end{array}$ & $\begin{array}{c}\text { Electrical conductivity } \\
{[\% \text { IACS }]}\end{array}$ \\
\hline Before-ECAP & Without ECAP processing & $124.9 \pm 3.8$ & $60.15 \pm 0.16$ \\
\hline $\boldsymbol{R T}$ & ECAP for 8 passes at room temperature & $188.8 \pm 4.7$ & $59.95 \pm 0.10$ \\
\hline $\boldsymbol{E T}$ & ECAP for 8 passes at 423 K & $188.4 \pm 0.3$ & $59.67 \pm 0.11$ \\
\hline Condition 1 & $\begin{array}{c}\text { ECAP for 4 passes at room temperature + } \\
\text { followed 4 passes at 423 K }\end{array}$ & $180.1 \pm 3.9$ & $59.80 \pm 0.10$ \\
\hline Condition 2 & $\begin{array}{c}\text { ECAP for 4 passes at 423 K + followed } \\
\text { 4 passes at room temperature }\end{array}$ & $176.3 \pm 1.0$ & $59.47 \pm 0.11$ \\
\hline Condition 3 & $\begin{array}{c}\text { ECAP for 6 passes at 423 K + followed } \\
\text { 2 passes at room temperature }\end{array}$ & $184.6 \pm 2.3$ & $60.07 \pm 0.09$ \\
\hline Condition 4 & $\begin{array}{c}\text { ECAP for 7 passes at 423 K + followed } \\
\text { 1 pass at room temperature }\end{array}$ & $182.3 \pm 1.7$ & $60.18 \pm 0.09$ \\
\hline Condition 5 & $\begin{array}{c}\text { ECAP for 1 pass at 423 K + followed } \\
\text { and then another 1 pass at 423 K }\end{array}$ & $181.2 \pm 1.8$ & $60.83 \pm 0.10$ \\
\hline
\end{tabular}

\section{Conclusion}

The energy-saving ECAP technology was used to replace the traditional heating treatment process to successfully produce the cable Al-Fe alloy. The evolutions of mechanical properties and electrical conductivity were studied and a suitable ECAP sequence was proposed to achieve the simultaneous improvement of strength and electrical conductivity based on the modification of conventional ECAP sequence. In this processing, the simple heating conduction was converted to thermo-mechanical energy transfer, so as to realise the good strength and conductivity matching of the cable aluminum alloy material. At the same time, it saves tens of heating treatment time, reduces energy consumption and improves production efficiency. The research results can be used for technology upgrading and low carbon production in cable industry due to the significantly time reduction of the energy-consuming heat treatment, which is expected to improve the quality and efficiency and realise industrial energy-saving and consumption reduction. 


\section{Acknowledgements}

This work was supported by the Fundamental Research Funds for the Central Universities [Grant number HEUCF201836], the Fundamental Research Funds for the Central Universities and Key Laboratory of Superlight Materials \& Surface Technology (Harbin Engineering University), Ministry of Education and Jiangsu Changfeng Cable Co. LTD.

\section{References}

[1] Broniszewski M, Werle S. Energy efficiency modernizations at the industrial plant: A case study. Ecol Chem Eng S. 2020;27(2):183-93. DOI: 10.2478/eces-2020-0011.

[2] Klugmann-Radziemska E, Rudnicka M. Energy yield generated by a small building integrated photovoltaic installation. Ecol Chem Eng S. 2020;27(3):335-46. DOI: 10.2478/eces-2020-0021.

[3] Rodziewicz T, Zaremba A, Wacławek M. Photovoltaics: Solar energy resources and the possibility of their use. Ecol Chem Eng S. 2016;23(1):9-32. DOI: 10.1515/eces-2016-0001.

[4] Liu T, Wang Q, Sui Y, Wang Q. Microstructure and mechanical properties of overcast 6101-6101 wrought Al alloy joint by squeeze casting. J Mater Sci Technol. 2016;32(4):298-304. DOI: 10.1016/j.jmst.2015.11.020.

[5] Singh D, Jayaganthan R. Effect of post cryorolling treatments on microstructural and mechanical behaviour of ultrafine grained Al-Mg-Si alloy. J Mater Sci Technol. 2014;30(10):998-1005. DOI: 10.1016/j.jmst.2014.03.009.

[6] Sabirov I, Murashkin MY, Valiev RZ. Nanostructured aluminium alloys produced by severe plastic deformation: New horizons in development. Mater Sci Eng A. 2013;560:1-24. DOI: 10.1016/j.msea.2012.09.020

[7] Murashkin MY, Sabirov I, Sauvage X, Valiev RZ. Nanostructured Al and Cu alloys with superior strength and electrical conductivity. Mater Sci. 2016;51(1):33-49. DOI: 10.1007/s10853-015-9354-9.

[8] Huang X, Hansen N, Tsuji N. Hardening by annealing and softening by deformation in nanostructured metals. Science. 2006;312(5771):249-51. DOI: 10.1126/science.1124268.

[9] Rhee H, Whittington WR, Oppedal AL, Sherif AR, King RL, Kim HJ, et al. Mechanical properties of novel aluminum metal matrix metallic composites: Application to overhead conductors. Materials Design. 2015;88:16-21. DOI: 10.1016/j.matdes.2015.08.109.

[10] Karnesky RA, Meng L, Dunand DC. Strengthening mechanisms in aluminum containing coherent Al3Sc precipitates and incoherent $\mathrm{Al}_{2} \mathrm{O}_{3}$ dispersoids. Acta Materialia. 2007;55(4):1299-308. DOI: 10.1016/j.actamat.2006.10.004.

[11] Samaee M, Najafi S, Eivani AR, Jafarian HR, Zhou J. Simultaneous improvements of the strength and ductility of fine-grained AA6063 alloy with increasing number of ECAP passes. Mater Sci Eng A. 2016;669:350-7. DOI: 10.1016/j.msea.2016.05.070.

[12] Lin G, Zhang Z, Wang H, Zhou K, Wei Y. Enhanced strength and electrical conductivity of Al-Mg-Si alloy by thermo-mechanical treatment. Mater Sci Eng A. 2016;650:210-7. DOI: 10.1016/j.msea.2015.10.050.

[13] Liu CH, Chen J, Lai YX, Zhu DH, Gu Y, Chen JH. Enhancing electrical conductivity and strength in Al alloys by modification of conventional thermo-mechanical process. Mater Des. 2015;87:1-5. DOI: 10.1016/j.matdes.2015.07.133.

[14] Valiev RZ, Murashkin MY, Sabirov I. A nanostructural design to produce high-strength Al alloys with enhanced electrical conductivity. Scr Mater. 2014;76:13-6. DOI: 10.1016/j.scriptamat.2013.12.002.

[15] Bobruk EV, Murashkin MY, Kazykhanov VU, Valiev RZ. Aging behavior and properties of ultrafine-grained aluminum alloys of Al-Mg-Si system. Rev Adv Mater Sci. 2012;31:109-15. Available from: www.ipme.ru/e-journals/RAMS/no_23112/03_23112_bobruk.html.

[16] Cubero-Sesin JM, Arita M, Horita Z. High strength and electrical conductivity of Al-Fe alloys produced by synergistic combination of high-pressure torsion and aging. Adv Eng Mater. 2015;17(12):1792-803. DOI: 10.1002/adem.201500103.

[17] Luo J, Gao J, Wang A, Huang J. Bulk nanostructured materials based on two-dimensional building blocks: a roadmap. ACS Nano. 2015;9(10):9432-6. DOI: 10.1021/acsnano.5b05259.

[18] Xu C, Schroeder S, Berbon PB, Langdon TG. Principles of ECAP-Conform as a continuous process for achieving grain refinement: Application to an aluminum alloy. Acta Mater. 2010;58(4):1379-86. DOI: 10.1016/j.actamat.2009.10.044. 
[19] Dadbakhsh S, Taheri AK, Smith CW. Strengthening study on 6082 Al alloy after combination of aging treatment and ECAP process. Mater Sci Eng A. 2010;527(18-19):4758-66. DOI: 10.1016/j.msea.2010.04.017.

[20] Valiev RZ, Islamgaliev RK, Alexandrov IV. Bulk nanostructured materials from severe plastic deformation. Prog Mater Sci. 2000;45(2):103-89. DOI: 10.1016/S0079-6425(99)00007-9.

[21] Shuai L, Li Z, Zhang DT, Tong YX, Li L. The mechanical property and electrical conductivity evolution of Al-Fe alloy between room temperature and elevated temperature ECAP. Vacuum. 2021;183:109813. DOI: 10.1016/j.vacuum.2020.109813.

[22] Liu W, Ma H, Walsh A. Advance in photonic crystal solar cells. Renew Sust Energy Rev. 2019;116:109436. DOI: $10.1016 /$ j.rser.2019.109436.

[23] Zhang X, Zang C, Ma H, Wang Z. Study on removing calcium carbonate plug from near wellbore by high-power ultrasonic treatment. Ultrason Sonochem. 2020:104515. DOI: 10.1016/j.ultsonch.2019.03.006.

[24] Ma H, Zhang X, Ju F, Tsai S-B. A study on curing kinetics of nano-phase modified epoxy resin. Sci Rep. 2018;8:3045. DOI: 10.1038/s41598-018-21208-0.

[25] Ma H, Tsai S-B. Design of research on performance of a new iridium coordination compound for the detection of $\mathrm{Hg}^{2+}$. Int J Env Res Public Health. 2017;14:1232. DOI: 10.3390/ijerph14101232.

[26] Baffari D, Reynolds AP, Masnata A, Fratini L, Ingarao G. Friction stir extrusion to recycle aluminum alloys scraps: energy efficiency characterization. J Manuf Processes. 2019;43:63-9. DOI: 10.1016/j.jmapro.2019.03.049.

[27] Srinivasan R, Cherukuri B, Chaudhury PK. Scaling up of equal channel angular pressing (ECAP) for the production of forging stock. Mater Sci Forum. 2006;503:371-8. DOI: 10.4028/www.scientific.net/MSF.503-504.371.

[28] Hakala M, Nygård K, Manninen S, Huitari S, Buslaps T, Nilsson A, et al. J Chem Phys. 2006:125:084504. DOI: 10.1063/1.2273627.

[29] Simeonov V. Chem Didact Ecol Metrol. 2019;24(1-2):7-21. DOI: 10.2478/cdem-2019-0001. 